\title{
Respon AVO dan Pemodelan Subsitusi Fluida dengan Menggunakan Teori Gassmann dan Differential Effective Medium pada Batuan Karbonat
}

\author{
M. Dhany Hambali ${ }^{1}$ \\ Teknik Perminyakan, Fakultas Teknik dan Desain, Institut Teknologi Sains Bandung, Bekasi, Indonesia \\ Email:dhambali@gmail.com
}

Informasi naskah:

Diterima

28 Mei 2019

Direvisi

28 Juli 2019

Disetujui terbit

04 Agustus 2019

Diterbitkan

07 Agustus 2019

\begin{abstract}
Abstrak
Pemodelan subsitusi fluida menjadi salah satu hal yang penting dalam studi mengenai seismik attribute. Pemodelan subsitusi fluida dapat melihat anomali dari respon Amplitude Versus Offset (AVO) dari batuan tersebut. Anomali dari Amplitude Versus Offset pada umumnya disebabkan karena kehadiran dari hidrokarbon atau fluida pada pori batuan. Pendekatan yang biasa digunakan untuk melakukan pemodelan subsitusi fluida adalah berdasarkan persamaan Gassmann yang menghubungkan antara modulus bulk pada saat saturasi dengan modulus bulk frame batuan dan properties dari fluida pengisi pori nya. Metode lain adalah Differential Effective Medium (DEM) yaitu berdasarkan penambahan inklusi fluida secara infinitedesimal pada matriks yang telah ada. Hasil pemodelan berupa analisa respon AVO dalam bentuk crossplot dari AVO gradient dan AVO intercept dari batuan tersebut. Hasil analisa pemodelan didapatkan bahwa pemodelan menggunakan Teori Gassmann memberikan kesalahan relatif rata-rata yang paling kecil dibanding dengan menggunakan Differential Effective Medium. Dari pemodelan respon AVO dapat diklasifikasikan bahwa batuan karbonat tersebut tergolong kelas I karena memiliki nilai AVO intercept yang positif dan AVO gradient yang negatif.
\end{abstract}

Kata-kunci: AVO, Differential Effective Medium, Teori Gassmann, 


\section{PENDAhuluan}

Metode geofisika yang secara umum digunakan untuk mencari minyak bumi adalah metode seismik refleksi. Metode seismik menggunakan sifat penjalaran gelombang untuk mendapatkan informasi mengenai geologi di bawah permukaan. Gelombang menjalar di bawah permukaan bumi pada batuan dengan nilai kecepatan yang berbeda bergantung pada parameter fisis dari batuan tersebut. Ketika gelombang tersebut melewati suatu fluida, perubahan perilaku gelombang akan terjadi bila dibandingkan dengan tidak melewati fluida. Jenis batuan yang banyak mengandung pori dan merupakan reservoir dari fluida adalah jenis batuan sedimen, contohnya adalah batuan karbonat. Upaya untuk memahami karakter dan sifat fisis suatu batuan reservoir dari data seismik memerlukan analisis mengenai fisika batuan.

Untuk meningkatkan pencarian terhadap minyak bumi, diperlukan adanya suatu informasi lain yang dapat memetakan bawah permukaan bumi secara lebih akurat dan dapat mendeteksi kandungan fluida yang terdapat di dalam batuan. Salah satu metode yang dipakai untuk meningkatkan kualitas pencitraan tersebut adalah menggunakan analisis Amplitude Versus Offset (AVO). AVO yaitu suatu metode dengan melihat hubungan antara sudut datang gelombang seismik dengan besarnya amplitudo seismik yang terdeteksi.

\subsection{Ruang Lingkup Kajian}

Dalam penelitian ini, ruang lingkup kajian meliputi mempelajari mengenai penjalaran gelombang seismik pada batuan karbonat, mempelajari mengenai struktur dan klasifikasi batuan karbonat, mempelajari mengenai pemodelan subsitusi fluida, dan mempelajari mengenai konsep analisis Amplitude Versus Offset (AVO). Dalam penelitian ini menggunakan MATLAB sebagai tools untuk pemodelan.

\subsection{Asumsi Dasar}

Asumsi dasar yang mendasari penelitian ini adalah dalam suatu pori batuan yang terdapat fluida terutama gas, maka akan terdapat anomali antara amplitudo gelombang seismik yang tercatat dengan jarak (offset), yaitu peningkatan offset akan mengakibatkan peningkatan koefisien refleksi dari seismik namun hal ini terbatas pada suatu jarak tertentu, serta terdapat sudut maksimum anomali ini dapat berlaku. Anomali tersebut terjadi karena perbedaan parameter batuan (seperti $\rho, V_{p}, V_{s}, \sigma$ dan lain-lain) antara batuan reservoir dengan lapisan gas.

\section{METODE}

Metode yang digunakan pada penelitian ini adalah dengan melakukan komputasi pemodelan batuan karbonat. Data input berupa data rock physics yang didapatkan dari data core dari sebuah sumur ekploitasi di batuan karbonat dan kemudian dilakukan forward modelling sehingga didapatkan informasi yang diperlukan. 


\subsection{Teori Gassmann}

Untuk melakukukan pemodelan subsitusi fluida menggunakan teori Gassmann, maka akan dilakukan beberapa langkah perhitungan untuk mendapatkan nilai $\mathrm{v}_{\mathrm{p}}$ dan $\mathrm{v}_{\mathrm{s}}$ yang diharapkan, langkah-langkah dalam melakukan pemodelan ini antara lain adalah ${ }^{1)}$ :

1. Menghitung $K_{\text {sat }}$ dan $\mu$ pada saat awal (keadaan in-situ)

2. Menghitung estimasi dari matrik $K_{0}$ ( dapat menggunakan metode Voigh-ReussHill)

3. Menghitung properti dari fluida ( $K_{\text {fluid }}$ dan $\rho_{\text {fluid }}$ )

4. Menghitung nilai modulus bulk frame $\left(K^{*}\right)$

5. Mengubah jenis fluida pengisi pori dan menghitung properti fluida yang baru

6. Menghitung modulus bulk saturasi $\left(K_{\text {sat }}\right)$ dan densitas yang baru

7. Menghitung kecepatan gelombang $\mathrm{P}$ dan gelombang $\mathrm{S}$

\subsection{Differential Effective Medium (DEM)}

Pemodelan subsitusi fluida menggunakan Differential Effective Medium didasari dari dua persamaan differential yang terkopel yang dapat dipecahkan secara numeric dengan metode Euler menjadi :

$$
\begin{aligned}
& K_{\left(y_{i+1}\right)}^{*}=K_{\left(y_{i}\right)}^{*}+\frac{\left(K_{2}-K_{\left(y_{i}\right)}^{*}\right.}{\left(1-y_{i}\right)} P_{\left(y_{i}\right)}^{* 2} \Delta y \\
& \mu_{\left(y_{i+1}\right)}^{*}=\mu_{\left(y_{i}\right)}^{*}+\frac{\left(\mu_{2}-\mu_{\left(y_{i}\right)}^{*}\right)}{\left(1-y_{i}\right)} Q_{\left(y_{i}\right)}^{* 2} \Delta y
\end{aligned}
$$

Dalam pemodelan ini, menggunakan geometri pori dengan bentuk bola (spherical), dengan nilai $\mathrm{P}$ dan $\mathrm{Q}$ adalah :

$$
\begin{gathered}
P_{(y)}^{(* 2)}=\frac{K^{*}(y)+\frac{4}{3} \mu^{*}(y)}{K_{2}+\frac{4}{3} \mu^{*}(y)} \\
Q_{(y)}^{* 2}=\frac{\mu_{(y)}^{*}+\xi^{*}}{\mu_{2}+\xi^{*}} \\
\xi_{(y)}^{*}=\frac{\mu_{(y)}^{*}\left(9 K_{(y)}^{*}+8 \mu_{(y)}^{*}\right)}{6\left(K_{(y)}^{*}+2 \mu_{(y)}^{*}\right)}
\end{gathered}
$$

Dalam model Differential Effective Medium ini, pada kondisi awal (initial) digunakan nilai modulus bulk saturasi, yaitu modulus bulk yang didapat dari rumusan ${ }^{2)}$ :

$$
K_{\text {initial }}=\rho\left(v_{p}^{2}-\frac{4}{3} v_{s}^{2}\right)
$$


sedangkan modulus geser initial didapatkan dari modulus geser saturasi pada saat kondisi awal sebelum dilakukan subsitusi fluida, yaitu ${ }^{2}$ :

$$
\mu_{\text {initial }}=\rho v_{s}^{2}
$$

Pada penelitian ini menggunakan dua jenis nilai dari $\mathrm{y}$, yaitu $\mathrm{y}=$ porositas dan $y=\phi / \phi$ dengan $\phi_{c}$ adalah porositas kritis dari batuan, dalam hal ini adalah batu gamping dengan nilai porositas ktitisnya adalah $0.4^{3)}$.

\subsection{Crossplot AVO intercept dan AVO gradient}

Untuk melakukan crossplot AVO intercept dan AVO gradient digunakan penyederhanaan persamaan Zoeppritz yaitu aproksimasi Aki-Richard dan Frasier ${ }^{4)}$ :

$$
R(\theta)=\frac{1}{2}\left(\frac{\Delta \alpha}{\alpha}+\frac{\Delta \rho}{\rho}\right)+\left(\frac{1}{2} \frac{\Delta \alpha}{\alpha}-4 \frac{\beta^{2}}{\alpha^{2}} \frac{\Delta \beta}{\beta}-2 \frac{\beta^{2}}{\alpha^{2}} \frac{\Delta \rho}{\rho}\right) \sin ^{2} \theta+\frac{1}{2} \frac{\Delta \alpha}{\alpha}\left(\tan ^{2} \theta-\sin ^{2} \theta\right)
$$

Maka dari persamaan tersebut :

AVO intercept adalah :

$$
\frac{1}{2}\left(\frac{\Delta \alpha}{\alpha}+\frac{\Delta \rho}{\rho}\right)
$$

AVO gradient adalah :

$$
\frac{1}{2} \frac{\Delta \alpha}{\alpha}-4 \frac{\beta^{2}}{\alpha^{2}} \frac{\Delta \beta}{\beta}-2 \frac{\beta^{2}}{\alpha^{2}} \frac{\Delta \rho}{\rho}
$$

Dengan

$$
\begin{aligned}
& \Delta \alpha=\frac{v_{p 2}-v_{p 1}}{2} \\
& \Delta \beta=\frac{v_{s 2}-v_{s 1}}{2} \\
& \Delta \rho=\frac{\rho_{2}-\rho_{1}}{2} \\
& \alpha=v_{p 2}+v_{p 1} \\
& \beta=v_{s 2}+v_{s 1} \\
& \rho=\rho_{2}+\rho_{1}
\end{aligned}
$$




\section{PEMBAHASAN DAN DISKUSI}

\subsection{Pemodelan Subsitusi Fluida}

Hasil pemodelan mengindikasikan subsitusi fluida menggunakan Teori Gassmann dan Differential Effective Medium menghasilkan kesalahan relatif yang bervariasi (dilihat dariTabel.1). Kehadiran clay pada batuan karbonat membuat estimasi dari model Gassmann menjadi overcorrected dikarenakan clay akan menyerap air dan menjaga air tersebut tetap berada di clay walaupun dalam keadaan pengeringan (drainage ${ }^{5}{ }^{5}$. Pengaruh dari $\mathrm{pH}$ juga dapat menimbulkan adanya interaksi anatara fluida dan frame dan berakibat pada perubahan nilai estimasi dari modulus shear dan modulus bulk ${ }^{5)}$. Bentuk pori batuan karbonat juga memberikan kontribusi dalam kesalahan pemodelan ini. Batuan karbonat memiliki jenis pori yang beragam, salah satu jenis pori tersebut adalah intercrystalin. Pori intercrystalin dan intergranular memiliki nilai modulus shear yang berkurang seiring dengan meningkatnya saturasi ${ }^{5)}$, hal ini bertentangan dengan asumsi dari teori Gassmann yang menyatakan bahwa modulus geser tidak berubah selama subsitusi fluida. Untuk model Differential Effective medium, diperlukan pemahaman yang lebih kompleks mengenai struktur dan geometri dari pori batuan karena dalam pemodelan ini geometri pori merupakan salah satu faktor yang memberikan pengaruh signifikan.

Tabel 1 : Kesalahan Relatif Pemodelan Subsitusi Fluida

\begin{tabular}{llll}
\hline No & & Gassmann & DEM \\
\hline 1 & Brine menjadi gas & $-6.732 \%$ & $-4.935 \%$ \\
2 & Brine menjadi oil & $19.715 \%$ & $11.061 \%$ \\
3 & Gas menjadi brine & $5.517 \%$ & $28.735 \%$ \\
4 & Gas menjadi oil & $8.026 \%$ & $-19.07 \%$ \\
5 & Oil menjadi brine & $10.345 \%$ & $-13.058 \%$ \\
6 & Oil menjadi gas & $10.917 \%$ & $-15.203 \%$ \\
\hline
\end{tabular}




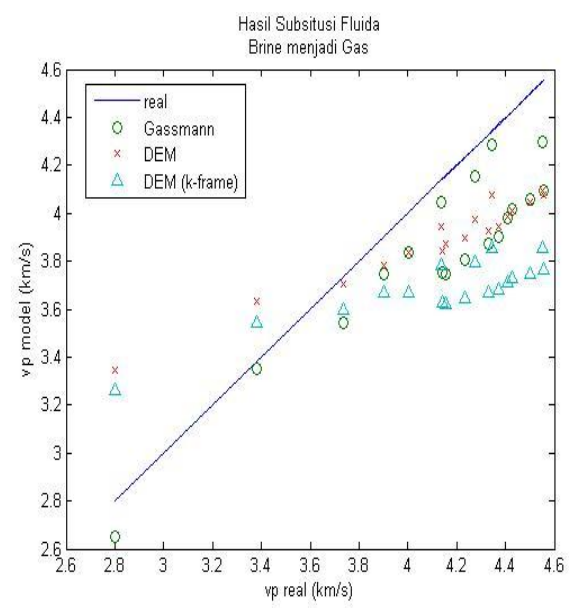

(a)

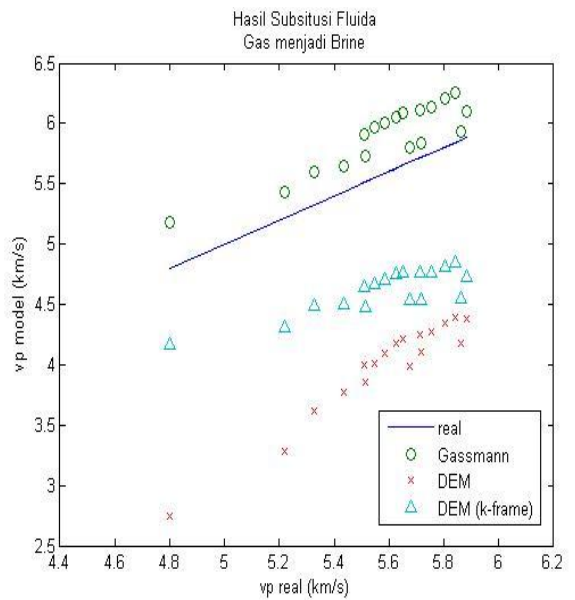

(c)

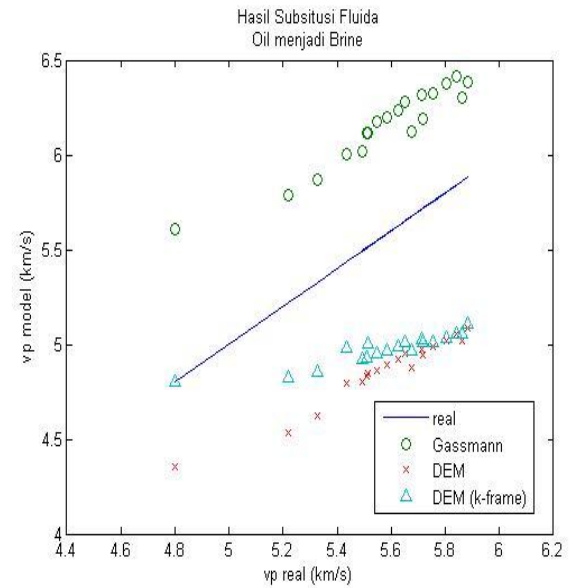

(e)

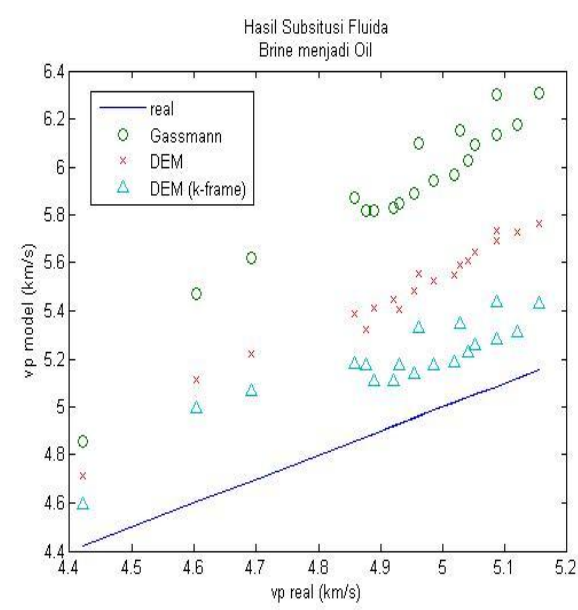

(b)

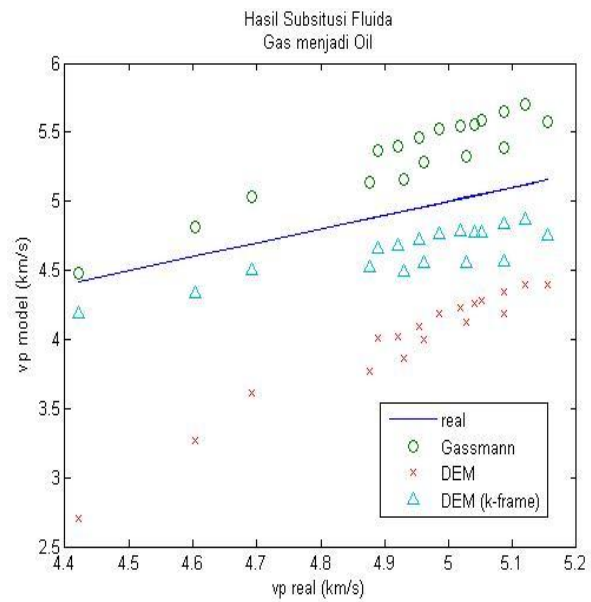

(d)

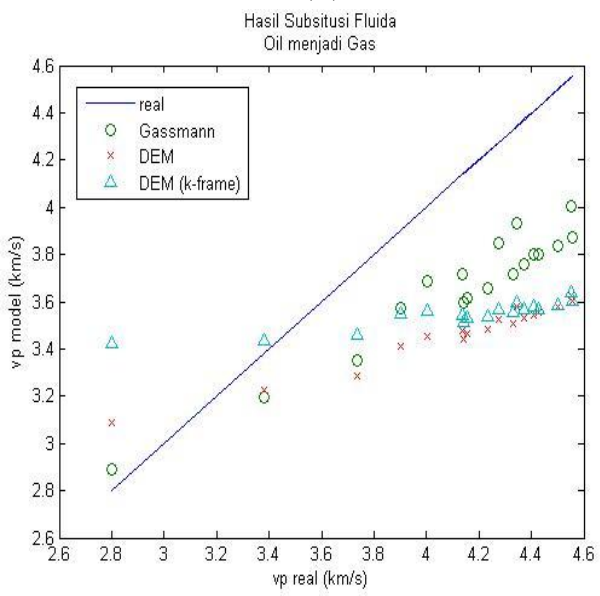

(f)

Gambar 1: Hasil Pemodelan Subsitusi Fluida (a) brine menjadi gas, (b) brine menjadi oil, (c) gas menjadi brine, (d) gas menjadi oil, (e) oil menjadi brine, (f) oil menjadi gas 


\subsection{Crossplot AVO Intercept dan AVO Gradient}

Dari hasil crossplot AVO intercept dan AVO gradient dapat dibandingkan antara crosplot pada kondisi awal (initial) dan crossplot pada kondisi setelah dilakukannya subsitusi fluida. Hasil yang didapat dari crossplot AVO intercept dan AVO gradient bervariasi namun keseluruhan pemodelan memiliki nilai kecenderungan yang konsisten, yaitu memiliki nilai AVO gradient yang negatif dan AVO intercept yang positif, yang membedakan adalah nilai untuk tiap AVO gradient dan AVO interceptnya. Hal tersebut secara konsisten menyatakan bahwa batuan karbonat diklasifikasikan sebagai AVO kelas I.

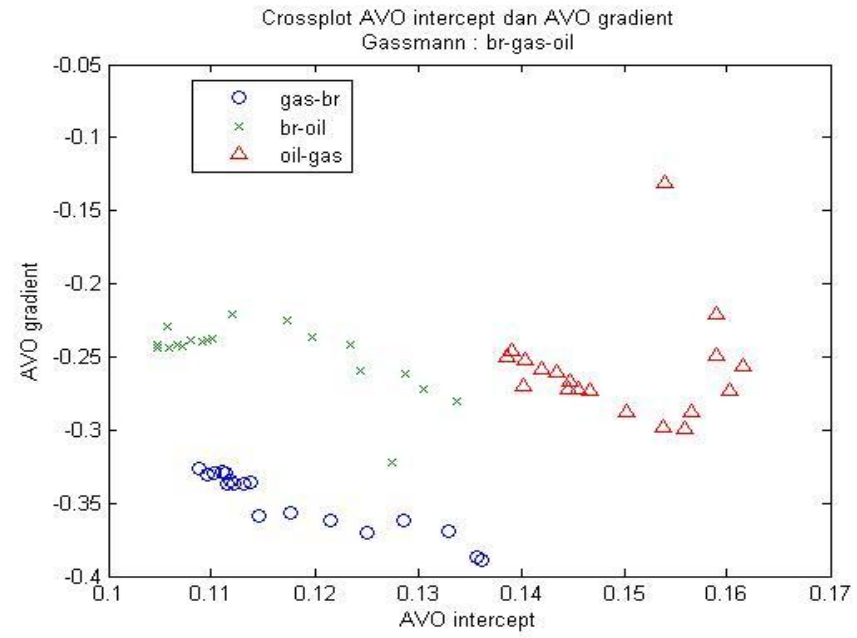

(a)

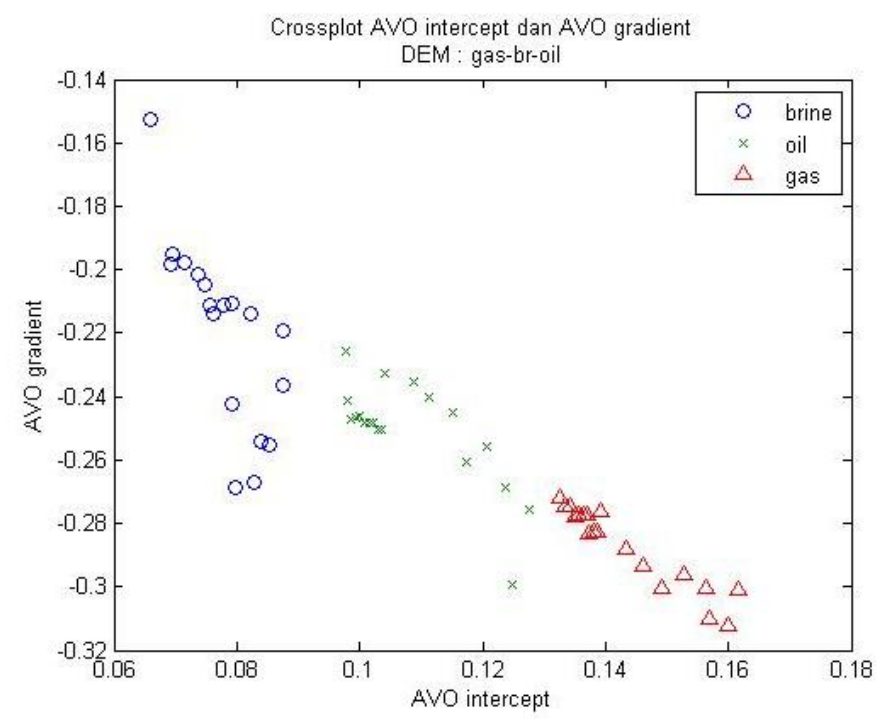

(b)

Gambar 2: Crossplot AVO Intercept dan AVO Gradient : (a) hasil pemodelan Gassmann, (b) hasil pemodelan DEM 


\section{KESIMPULAN}

Setelah dilakukan pemodelan subsitusi fluida dan respon AVO pada sample batuan karbonat, maka dapat diambil beberapa kesimpulan, antara lain model Gassmann menghasilkan estimasi nilai kecepatan gelombang seismik yang terbaik bila dibandingkan dengan model Differential Effective Medium (DEM). Dari hasil respon crossplot AVO, didapatkan kesimpulan bahwa kelas AVO untuk sampel batuan karbonat tersebut adalah kelas 1 yang memiliki AVO intercept yang bernilai positif dan AVO gradient yang negatif.

\section{UCAPAN TERIMA KASIH}

Penulis mengucapkan terimakasih kepada Wave Inversion and Subsurface Fluid Imaging Research (WISFIR) Departemen Fisika Institut Teknologi Bandung yang telah membantu pada penelitian ini.

\section{DAFTAR PUSTAKA}

1) Smith,T.M., Sondergeld, C.H., Rai,C.S., (2003), Gassmann Fluid Subsitutions: A Tutorial, Geophysics, 68, 430-440.

2) Telford,W.M.,Geldart, L.P.,Sheriff, R.E. (1990), Applied Geophysics $2^{\text {nd }}$ edition, Cambridge University Press.

3) Wang, Z., Nur, A., Seismic and Acoustic Velocities in Reservoir Rocks Vol. 3, Recent Development Geophysics reprint series, Society of Exploration Geophysics.

4) Castagna,J.P.,Backus,M.M., (1993), Offset-Dependent Reflectivity-Theory and Practice of AVO Analysis, Society of Exploration Geophysics.

5) Misaghi,A et al., (2010), Comparison of Rock Physics Models for Fluid Substitution in Carbonate Rocks, Exploration Geophysics,41,146-154.

6) Castagna,J., Swan,H.W., Foster, D.J., (1998), Framework for AVO Gradient and Intercept Interpretation, Geophysics, 63, 948-956.

7) Rutherford, S. R., and Williams, R. H., (1989), Amplitude-versus-offset Variations in Gas Sands, Geophysics, 54, 680-688.

8) Kumar,D., (2006), A Tutorial on Gassmann Fluid Substitution : Algorithm and Matlab Code , Geohorizon, January 2006/4.

9) Wu, T. T., (1966), The Effect of Inclusion Shape on The Elastic Moduli of a Two-Phase Material, International Journal of Solids and Structures, 2, 1-8. doi:10.1016/0020-7683(66)90002-3.

10) Berryman, J. G., (1995), Differential Effective Medium Modelling of Rock Elastic Moduli with Critical Porosity Constraints, Geophysical Research Letters, 2, 555-558.

11) Fauzi,U., (2002), Diktat Kuliah Fisika Batuan, ITB. 